\title{
Prevalence and potential for aflatoxin contamination in groundnuts and peanut butter from farmers and traders in Nairobi and Nyanza provinces of Kenya
}

\author{
J. W. Ndung' ${ }^{1 *}$, A. O. Makokha' ${ }^{1}$, C. A. Onyango ${ }^{1}$, C. K. Mutegi ${ }^{2}$, J. M. Wagacha ${ }^{3,4}$, M. E. Christie ${ }^{5}$, \\ A. K. Wanjoya ${ }^{6}$ \\ 1 Department of Food Science and Technology, Jomo Kenyatta University of Agriculture and Technology \\ (JKUAT), P.O Box 62000 - 00200, Nairobi, Kenya \\ ${ }^{2}$ Kenya Agricultural Research Institute (KARI), P. O. Box 57811 - 00200 Nairobi, Kenya \\ ${ }^{3}$ International Crops Research Institute for the Semi Arid Tropics (ICRISAT), P.O Box 39063 - 00623, Nairobi, \\ Kenya \\ ${ }^{4}$ School of Biological Sciences, University of Nairobi, P.O. Box 30197 - 00100 Nairobi, Kenya \\ 5 Office of International Research, Education and Development, Virginia Tech, Blacksburg, VA 24061, USA \\ ${ }^{6}$ Department of Statistics and Actuarial Science, Jomo Kenyatta University of Agriculture and Technology \\ (JKUAT), P.O Box 62000 - 00200, Nairobi, Kenya \\ *Corresponding author: johnsonweru@yahoo.com
}

Original submitted in on 22 ${ }^{\text {nd }}$ March 2013 Published online at www.m.elewa.org on 29th May 2013.

http://dx.doi.org/10.4314/jab.v65i0.89579

\begin{abstract}
Objective: Most of the peanut butter marketed in Nairobi is processed in cottage industry and its aflatoxin contamination status has not been documented. This study was therefore conducted to determine the status of aflatoxin contamination in groundnuts and peanut butter in Nairobi and Nyanza. Methodology and results: Eighty two fresh samples comprising raw and roasted groundnuts and peanut butter were obtained from market outlets and cottage processors in Nairobi and Nyanza regions. The marketers and processors were asked for information on the source of groundnuts. The incidence of Aspergillus section Flavi was determined using standard laboratory methods. Defective nuts in raw groundnuts were determined by manual sorting. Aflatoxin analysis was done using competitive ELISA technique. Groundnuts in Nairobi were imported from Malawi while those Nyanza were grown in the region. The fungal species isolated from the samples were: Aspergillus flavus ( $L$ and $S$ strains), $A$. parasiticus, A. niger, A. tamari, A. alliaceus, A. caeletus and Penicillium spp. The percentage of defective nuts among all unsorted groundnuts ranged from $0.0 \%$ to $26.3 \%$. The mean percent defective nuts was higher for Nairobi samples than Nyanza. Aflatoxin levels in all samples ranged from 0 to $2377.1 \mu \mathrm{g} / \mathrm{kg}$. The mean aflatoxin level was higher for raw samples from Nairobi than Nyanza. The source of groundnuts and defective nuts were positively associated with aflatoxin levels.

Conclusions and application of findings: The source of groundnuts and presence of defective nuts were identified as the main factors influencing increased aflatoxin contamination in the cottage industry. Mechanisms for inspection and certification of imported groundnuts should be put in place accompanied by effective monitoring for compliance to set aflatoxins standards. All the market players should sort their groundnuts before selling or processing in order to reduce aflatoxin contamination of peanut butter. Key words: Aflatoxin, cottage industry, groundnut, peanut butter.
\end{abstract}




\section{INTRODUCTION}

Groundnut (Arachis hypogaea L.) is an oilseed produced all over the world and is also consumed in form of snacks such as salted nuts, confectionary sauce, and peanut butter (Campos-Mondragón et al., 2009). Botanically, groundnut is a legume although it is widely identified as a nut and has similar nutrient profile with tree nuts (Ros, 2010). Peanut butter is made by grinding dry roasted groundnuts into a paste (Mutegi et al., 2009). Groundnuts that are used as raw materials for peanut butter processing are liable to colonization by fungal molds during handling, storage and transportation, exposing them to the risk of contamination with aflatoxin (Polixeni \& Panagiota, 2008; Mutegi et al., 2012). Groundnuts can be contaminated with aflatoxin pre- and post-harvest and the risk of contamination increases along the marketing chain due to poor handling practices (Kladpan et al., 2004; Kaaya et al., 2006). The main aflatoxin producing fungi in groundnuts are Aspergillus flavus, A. parasiticus and A. nomius (CAST, 1998) which mostly infect groundnuts as a complex (Varga et al., 2012). Mutegi et al. (2012) reported A. flavus L-strain, A. flavus S-strain, and $A$. niger as the major fungal pathogens infecting groundnuts and groundnut products from Busia and Homa Bay districts in Western Kenya. Aspergillus flavus and aflatoxin have been reported in groundnuts in Sudan (Omer, 2001; Omer et al., 2001) and Egypt (Abdelhamid, 1990) and in peanut butter in Sudan (Eshafie et al., 2011).Aspergillus flavus, the main producer of aflatoxin, only grows in groundnuts when the moisture content exceeds $9 \%$ and has optimum growth conditions of between 25 and $30^{\circ} \mathrm{C}$, and water activity of 0.99 with a minimum of $0.83 \mathrm{a}_{\mathrm{w}}$, while production of aflatoxin occurs optimally at $25^{\circ} \mathrm{C}$ and $0.99 \mathrm{a}_{\mathrm{w}}$ with a minimum of $0.87 \mathrm{a}_{\mathrm{w}}$ (Ribeiro et al., 2006). The warm and humid environmental conditions in Africa are ideal for growth of $A$. flavus making aflatoxin contamination of food, including groundnuts, a widespread problem across the continent (Gordon, 2003; Bankole et al., 2006; Wagacha \& Muthomi, 2008). Aflatoxins are among the most prevalent carcinogens (Ribeiro et al., 2006). Acute exposure of humans to aflatoxins leads to outbreak of a disease condition known as aflatoxicosis contributing significantly to the disease burden in Africa (Mehan et al., 1991; Gordon, 2003). Chronic effects of aflatoxins result from continuous exposure to relatively low levels of toxins over a prolonged period (Mehan et al., 1991). Some of the common effects of chronic aflatoxicosis include impaired food conversion, slower rates of growth, and a decrease in absorption of various micronutrients (Jolly et al., 2007). Aflatoxin contamination of groundnuts therefore poses a risk to human health and has been identified as a major constraint to trade in Africa (Mutegi et al., 2009). In a recent study (Mutegi et al. 2012), 37\% of groundnuts and their products including peanut butter and peanut flour sampled from Nairobi, Nyanza and Western Kenya did not meet the 10 $\mu \mathrm{g} / \mathrm{kg}$ total aflatoxin limit set by the Kenya Bureau of Standards (KEBS, 2007). Peanut butter is one of the main products of groundnut processing (Campos-Mondragón et al., 2009) which is used as a sauce or spread in many households in Kenya (Mutegi et al., 2010). Most of the peanut butter consumed in Nairobi is produced in the cottage industry (Mutegi et al., 2010). If raw groundnuts are contaminated with aflatoxins, there is a high risk of exposure to the consumer through consumption of peanut butter processed from such groundnuts. Practices such as poor storage and handling within the peanut butter cottage industry could contribute to further aflatoxin contamination of peanut butter.

There are many cottage industries in Nairobi that produce peanut butter (Mutegi et al., 2010). High aflatoxin levels up to $22 \mu \mathrm{g} / \mathrm{kg}$ in groundnut products such as roasted nuts and peanut butter have been reported in Nairobi (Mutegi et al., 2010). Previous studies have not investigated the status of aflatoxin contamination in the peanut butter cottage industry in Nairobi. The objectives of this study were therefore to: (i) establish the aflatoxin contamination of various products from the peanut butter cottage industry in Nairobi and Nyanza; (ii) establish the aflatoxin contamination of raw groundnuts from market outlets that are used to process peanut butter in the cottage industry in Nairobi. 


\section{MATERIALS AND METHODS}

Study sites: The study was conducted in Nairobi and Nyanza (Kisii, Rongo, Homabay and Ndhiwa districts) provinces of Kenya. Nairobi is a major trade center for groundnuts with many cottage industries that process peanut butter. Demand for peanut butter in Nairobi is high. Nyanza province is the main groundnut producing region in Kenya and it would therefore be expected to be the main source of raw groundnuts for processing peanut butter in Nairobi, hence, it was chosen as a study site.

Sample collection: Twelve peanut butter cottage processors and 22 groundnut traders in Nairobi were involved in the study. Additionally, groundnut samples were taken from 24 farmers and traders from four districts in Nyanza. A list of 22 peanut butter cottage processors in Nairobi was provided by Kenya Bureau of Standards (KEBS), the standards regulatory body in Kenya. The 22 processors were contacted with 12 consenting to participate in the study thereby constituting the study group within the peanut butter cottage industry in Nairobi. The cottage processors provided information on where they sourced their raw groundnuts, data which was used as the basis of identifying the traders. Nyamakima and Gikomba were identified as the major groundnut markets in Nairobi.

Sampling of groundnuts and groundnut products: A total of 82 peanut samples were randomly taken from different market outlets which were purposively selected in Nairobi and Nyanza regions as follows: 24 raw groundnut samples from retailers in Nyanza region; 23 unsorted raw groundnut samples from wholesalers in Nyamakima market in Nairobi and 11 sorted raw groundnut samples from wholesalers in Gikomba market in Nairobi. Five (5) raw groundnuts, 8 roasted groundnuts, and 11 peanut butter samples were obtained from the cottage processors in Nairobi. For wholesalers who stocked large groundnut lots (> than 40 bags), a $1 \mathrm{~kg}$ representative sample was obtained by sampling different portions of a consignment. At least nine subsamples were obtained from a $100 \mathrm{~kg}$ sack of groundnuts using a sampling probe. Three subsamples were obtained from the top, middle, and bottom portions of the sack, respectively. The subsamples were thoroughly mixed to form a representative sample from each wholesaler. For the cottage processors whose batches were small (handling less than $300 \mathrm{~kg}$ of groundnuts per month), each batch of groundnuts was mixed thoroughly for homogeneity before drawing a $1 \mathrm{~kg}$ sample. The samples were delivered to the laboratory for analysis in Kraft papers. For peanut butter, two packaged containers weighing 400 grams each were randomly picked from a batch. All the samples were stored for a week at $4^{\circ} \mathrm{C}$ in their original form before analysis.

Determination of defective nuts: The presence of defective nuts in unsorted raw groundnuts was determined by manual sorting according to KEBS standards (KEBS, 2007). The $1 \mathrm{~kg}$ sample obtained from the market was mixed thoroughly to ensure homogeneity. A $250 \mathrm{~g}$ sub-sample was drawn and all the defective nuts sorted by hand and weighed. The proportion of defective nuts per sample was calculated as the weight of defective nuts (g) divided by $250 \mathrm{~g}$, and multiplied by 100 . The defects were further classified as broken, discolored, or shriveled.

Microbial assay: Fungal species were isolated on the semi selective modified dichrolan rose Bengal (MDRB) agar (Horn \& Dorner, 1998). The medium was prepared by mixing $10 \mathrm{~g}$ glucose, $2.5 \mathrm{~g}$ peptone, $0.5 \mathrm{~g}$ yeast extract, $1 \mathrm{~g} \mathrm{KH}_{2} \mathrm{PO}_{4}, 0.5 \mathrm{~g} \mathrm{MgSO}_{4} .7 \mathrm{H}_{2} \mathrm{O}$, $20 \mathrm{~g}$ agar and $25 \mathrm{mg}$ Rose Bengal in 1 liter of distilled water. The medium was autoclaved for 20 minutes at $121^{\circ} \mathrm{C}$ and $15 \mathrm{psi}$ and cooled in a water bath to $50^{\circ} \mathrm{C}$. To inhibit bacterial growth and ensure the medium was semi-selective for Aspergillus section Flavi, 10 $\mathrm{ml}$ of $4 \mathrm{mg} / \ell$ dichloran (in acetone), $10 \mathrm{ml}$ of $40 \mathrm{mg} / \ell$ streptomycin (in distilled water) and $10 \mathrm{ml}$ of $1 \mathrm{mg} / \ell$ chlorotetracycline (in distilled water) were added to the medium through a sterile $0.25 \mu \mathrm{m}$ syringe filter after cooling to $50^{\circ} \mathrm{C}$. The medium was then poured into $90 \mathrm{~mm}$-diameter sterile Petri plates and allowed to settle overnight in a sterile hood before use. One gram of ground sample or paste was weighed into a sterile dilution tube and $9 \mathrm{ml}$ of sterile peptone water added to make the first dilution. The sample suspension was then vortex-mixed to ensure homogeneity. A second dilution was prepared by drawing $1 \mathrm{ml}$ from the first dilution and adding it into $9 \mathrm{ml}$ of sterile peptone water. Then, $0.1 \mathrm{ml}$ of each sample dilution was inoculated onto the MDRB agar medium in six replicates per sample for each dilution, and incubated for 6 days at $30^{\circ} \mathrm{C}$.

Reference cultures of Aspergillus section Flavi obtained from the Centre for Agricultural Bioscience International (CABI), Plant Pathology Laboratory, were cultured on the MDRB medium at the time the samples were plated. The reference cultures included A. flavus ( $\mathrm{S}$ and $\mathrm{L}$ strains), A. parasiticus, A. tamarii, $A$. alliaceus, and $A$. caeletus. The shape, margins, elevation, pigmentation, texture, and pattern of growth of the fungal colonies were used in identifying the Aspergillus species and for $A$. flavus, distinguishing between the $L$ and $S$ strains. A tally counter was used 
to count the total number of colony forming units (CFU) per Petri plate. The number of colonies of $A$. flavus ( $S$ and $L$ strains), A. parasiticus, $A$. tamarii, $A$. alliaceus, and $A$. caeletus was recorded and their population determined per gram of groundnuts. The population of Penicillium spp. and other fungal species was also recorded for each sample.

Determination of aflatoxin levels: A representative $200 \mathrm{~g}$ sub-sample was drawn from each homogenous sample and ground into a fine powder using a dry mill kitchen grinder (Kanchan Multipurpose Kitchen Machine, Kanchan International Limited, Mumbai, India). Grinding was not required for peanut butter paste samples. The powder (or paste) was then triturated in $70 \%$ methanol $(\mathrm{v} / \mathrm{v} 70 \mathrm{ml}$ absolute methanol in $30 \mathrm{ml}$ distilled water) containing $0.5 \% \mathrm{w} / \mathrm{v}$ potassium chloride in a blender, until thoroughly mixed. The extract was transferred to a conical flask and shaken for $30 \mathrm{~min}$ at $300 \mathrm{rpm}$. The extract was then filtered through Whatman No. 41 filter paper and

\section{RESULTS AND DISCUSSION}

Sources and types of groundnuts used in the cottage industry in Nairobi: Groundnuts used in the peanut butter cottage industry in Nairobi were bought from wholesalers within the city who in turn sourced the groundnuts from Malawi. The demand for groundnuts and groundnut products in Nairobi is high and therefore the traders said that relied on imported groundnuts for their supply since it was more sustainable than sourcing locally. Groundnuts produced in Nyanza were traded in the region and did not reach the Nairobi wholesale markets and consequently the traders reported that they imported groundnuts from Malawi, in the study period. This is consistent with previous reports that groundnuts traded in Nairobi are hardly produced in Kenya but are purchased from neighboring countries (Mutegi et al., 2012). The groundnut traders in Nairobi comprised of wholesalers and retailers. The groundnut wholesalers were found in Nyamakima and Gikomba markets; with the latter doubling up as a retail market where groundnuts were sorted before selling. The raw groundnuts in Gikomba had been sourced from wholesalers in Nyamakima market. Other retail markets were found in Burma, Maringo, Kawangware, and Kikuyu. Different types of groundnuts were sampled from the cottage industry and markets in Nairobi (Fig. 1). The local names of the groundnut types, as used by the traders were: Pink regular, Pink large, Red regular, Red small and Red mixed. Pink regular and Red regular were the diluted 1:10 in phosphate buffered saline containing $500 \mu \mathrm{l} / \mathrm{l}$ Tween 20 (PBS-Tween) and analyzed for aflatoxin level based on Enzyme Linked Immunosorbent Assay, ELISA (Waliyer \& Reddy, 2009). The aflatoxin results were classed based on EU $(\leq 4 \mu \mathrm{g} / \mathrm{kg})$ and KEBS $(\leq 10 \mu \mathrm{g} / \mathrm{kg})$ standards.

Statistical analyses: Data were subjected to analysis of variance (ANOVA) using the SAS general linear model (GLM) procedure (Statistical Analysis System, The SAS Institute, Cary, NC, USA). The Tukey's studentized range (Honestly Significant Difference, HSD) test was used as post ANOVA technique for comparison of pairs of means. The ttest procedure was used to compare two means. Skewed data were transformed to $\log _{10}$ before data analysis and separation of means. Aflatoxin levels were compared with the maximum safe limits based on European Union (EC, 2010) and KEBS (KEBS, 2007) standards.

predominant types $(45 \%)$ of groundnuts both in Nairobi and Nyanza markets.

Defective kernels in unsorted raw groundnuts: There was no significant $(p \geq 0.05)$ difference in the proportion of defective nuts among the unsorted groundnut samples from markets in Nairobi and Nyanza (Table 1). Broken nuts were the most frequent $(47 \%)$ type of defective nuts possibly due to poor handling practices e.g. threshing and transportation. Whitaker et al. (1997) reported that broken nuts are a high risk factor to aflatoxin contamination. Overall, discolored and shriveled nuts constituted 23 and $30 \%$ of the defects, respectively. The proportion of defective nuts did not meet the KEBS threshold of $2 \%$ for raw groundnuts (KEBS, 2007). Higher than the recommended proportion of defective nuts could lead to higher aflatoxin contamination levels in groundnuts and groundnut products. Turner et al. (2005) reported that hand sorting reduced the amount of defective nuts which translated to reduced aflatoxin levels. The researchers observed that use of simple methods such as hand sorting, proper sun-drying on mats, and storage in natural-fiber bags reduced aflatoxin exposure in West Africa villages by more than $50 \%$. A similar study by Galvez et al. (2003) developed a manual sorting procedure where raw groundnuts were blanched at $140^{\circ} \mathrm{C}$ for 25 minutes in preheated roasters, cooled, de-skinned manually and then sorted. The procedure reduced aflatoxin levels in groundnuts from $300 \mu \mathrm{g} / \mathrm{kg}$ to undetectable levels. 

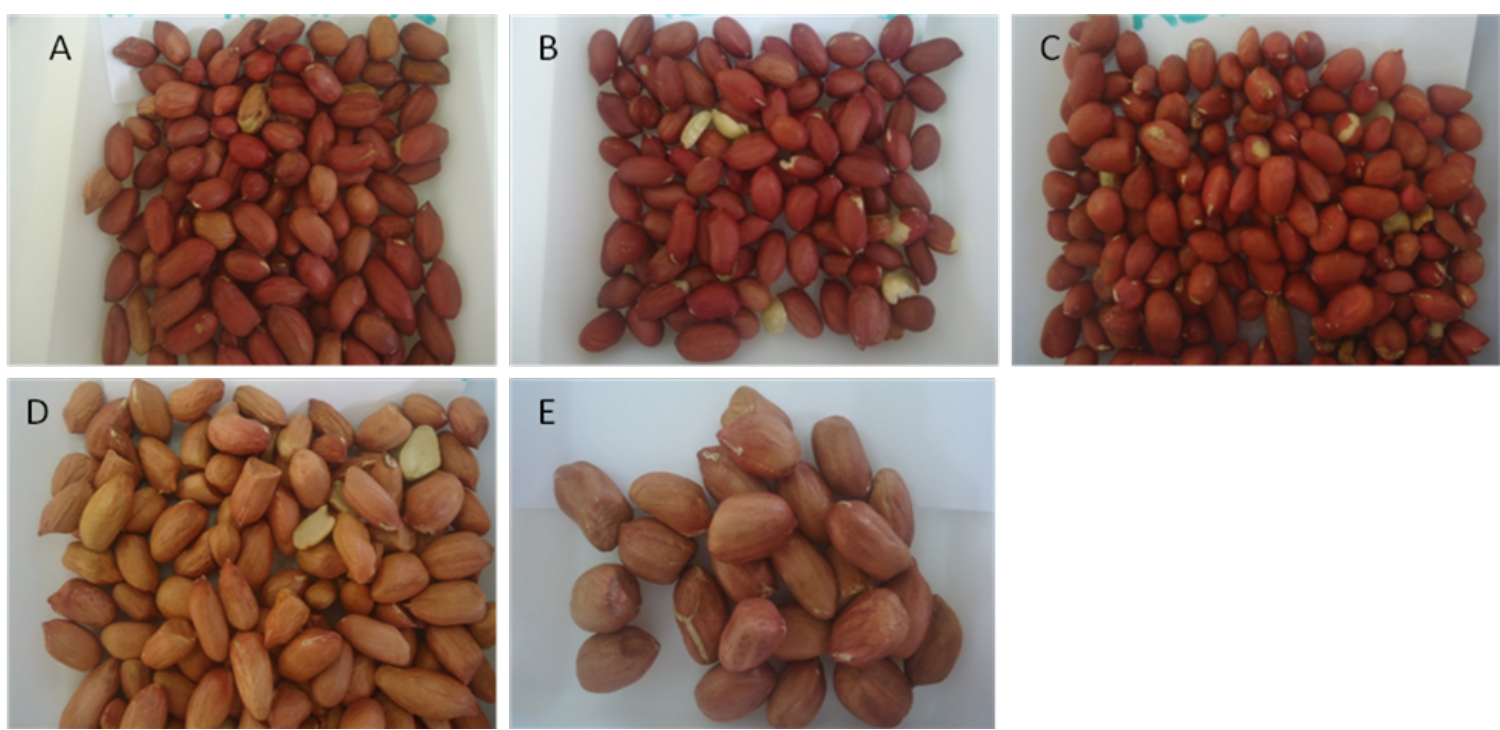

Figure 1: Major groundnut types traded in Nairobi and Nyanza markets in Kenya. (A) Red regular, (B) Red mixed, (C) Red small, (D) Pink regular, (E) Pink large.

Table 1: Proportion (\%) of defective nuts and types of defects in unsorted raw groundnut samples from markets in Nairobi and Nyanza regions.

\begin{tabular}{llrcccr}
\hline Sample source & Sample type & Defective & \multicolumn{3}{c}{ Types of defects } & n \\
\cline { 4 - 6 } & & nuts & Broken & Shriveled & Discolored & \\
\hline Cottage industry & Pink regular & $13.7 \pm 1.7 \mathrm{a}$ & 48.0 & 30.0 & 22.0 & 3 \\
& Red small & $7.7 \pm 0.0 \mathrm{a}$ & 50.0 & 27.0 & 23.0 & 1 \\
Nairobi wholesale & Pink regular & $15.2 \pm 1.7 \mathrm{a}$ & 45.5 & 32.3 & 22.2 & 11 \\
outlets & Red regular & $16.8 \pm 1.9 \mathrm{a}$ & 50.3 & 26.7 & 23.0 & 12 \\
Nyanza retail & Pink large & $15.9 \pm 0.2 \mathrm{a}$ & 45.0 & 32.1 & 22.9 & 3 \\
outlets & Pink regular & $12.6 \pm 1.9 \mathrm{a}$ & 47.6 & 28.7 & 23.7 & 9 \\
& Red regular & $12.5 \pm 7.1 \mathrm{a}$ & 44.1 & 33.9 & 22.0 & 9 \\
& Red mixed & $6.6 \pm 0.9 \mathrm{a}$ & 46.0 & 30.5 & 23.5 & 3 \\
\hline Mean & & $12.63 \pm 1.9$ & 47.1 & 30.2 & 22.8 &
\end{tabular}

${ }^{1}$ Values are means \pm SE. Values accompanied by the same letter within the column are not significantly different $(p \geq 0.05)$.

Population of fungal species in groundnuts and peanut butter: Seven Aspergillus species were isolated from groundnut and peanut butter samples (Table 2). They included $A$. flavus $S$ strain (mean $=$ $1230 \mathrm{CFU} / \mathrm{g}$ ), A. flavus $\mathrm{L}$ strain $(\mathrm{mean}=689 \mathrm{CFU} / \mathrm{g})$, A. parasiticus (mean $=122 \mathrm{CFU} / \mathrm{g}), A$. niger $($ mean $=$ $81 \mathrm{CFU} / \mathrm{g}$ ), A. tamarii (mean $=72 \mathrm{CFU} / \mathrm{g}), A$. alliaceus (mean $=25 \mathrm{CFU} / \mathrm{g}$ ), and $A$. caeletus (mean $=1 \mathrm{CFU} / \mathrm{g}$ ). The population of $A$. flavus $S$ strain was significantly $(p \leq 0.05)$ higher in unsorted groundnuts from Nairobi markets than from Nyanza. It takes a short time for groundnuts in Nyanza to reach the market as opposed to the long time taken for groundnuts from Malawi to reach Nairobi markets. The long time can predispose groundnuts to infection by the Aspergillus fungi especially if handling conditions are poor for instance during transport.
Penicillium spp. were isolated in high frequency in most of the samples (Mean $=19026 \mathrm{CFU} / \mathrm{g}$ ). Other fungi isolated from the groundnuts included Fusarium spp., Trichoderma spp., Rhizopus spp. and Mucor spp. The presence of these other fungi in large amounts is a clear indication of poor handling, e.g. poor hygiene and storage, which exposes the nuts to conditions favorable for fungal growth. However, the occurrence of a mixture of fungal organisms is deemed to reduce mycotoxin production (Mirocha et al., 1974; Raper et al., 1965). Some Fusarium strains can produce mycotoxins, such as fumonisins, trichothecenes and zearalenones, which are associated with mycotoxicoses in humans or domestic animals (Antonio et al., 2003). Toxigenic Penicillium species produces mycotoxins such as ochratoxins, citrinin, and patulin (Antonio et al., 2003). 
Therefore the presence of Penicillium in groundnuts poses a serious problem to human health. The occurrence of Rhizopus spp. and Mucor spp. can be used as indicators of potential presence of aflatoxins (Kane et al., 2006). No fungal pathogens were isolated from roasted groundnuts which could be attributed to heat processing during roasting. During roasting of groundnuts for peanut butter production, nuts are exposed to dry heat at temperatures of 120 Incidence of Aspergillus section Flavi in groundnuts and peanut butter: The incidence of Aspergillus section Flavi in various samples ranged from 0 to $80 \%$ (Table 3). Unsorted raw groundnuts sampled from Nairobi were the most infected: $A$. flavus $\mathrm{L}$ strain $(69.5 \%)$, A. flavus S strain $(65.0 \%)$, and $A$. parasiticus (30.0\%). Raw groundnuts from the cottage industry recorded the highest incidence $(80 \%)$ of $A$. flavus $S$ strain followed by unsorted groundnuts from Nairobi wholesale market (65\%). Aspergillus flavus $\mathrm{L}$ strain was the most frequently isolated $(69.5 \%)$ pathogen from unsorted groundnut samples from Nairobi wholesale market. The incidence of $A$. flavus ( $S$ and $L$ strains), and $A$. parasiticus, the three main aflatoxin producers, was higher in raw groundnuts sampled from markets in Nairobi than from Nyanza. Additionally, the incidence of $A$. flavus $150^{\circ} \mathrm{C}$ and above (Okello et al., 2010). However, fungal pathogens were isolated from peanut butter which is made immediately after the roasting step. This could be attributed to recontamination during processing. Indirect contamination is common in oilseeds and cereals in Africa and is the main entry point of mycotoxins in human dietary systems (Smith \& Moss, 1985).

( $S$ and $L$ strains) was higher in unsorted groundnuts than in sorted groundnuts from Nairobi wholesale market. This could be attributed to the fact that unsorted groundnuts are more prone to infection by aflatoxigenic fungi than sound kernels (Whitaker et al., 1997). Sorting groundnuts removes defective nuts and is effective in reducing aflatoxin contamination (Turner et al., 2005; Galvez et al., 2003). Members of Aspergillus section Flavi mainly $A$. flavus and $A$. parasiticus are the major producers of aflatoxin in groundnuts (Passone et al., 2010). Aspergillus flavus produces only B-type aflatoxins and it is the second leading cause of human aspergillosis (Hedayati et al., 2007; Pasqualotto \& Denning, 2008; Krishnan et al., 2009) while A. parasiticus produces both B- and G-type aflatoxins (Ehrlich et al., 2004; Frisvad et al., 2005).

Table 3: Incidence (\%) of Aspergillus flavus ( $\mathrm{L}$ and $\mathrm{S}$ strains) and A. parasiticus in groundnut and peanut butter samples from Nairobi and Nyanza provinces, Kenya.

\begin{tabular}{|c|c|c|c|c|c|}
\hline Sample source & Sample description & $\begin{array}{l}\text { A. flavus } \\
\text { L strain }\end{array}$ & $\begin{array}{l}\text { A. flavus } \\
\text { S strain }\end{array}$ & A. parasiticus & Total (n) \\
\hline \multirow[t]{3}{*}{ Cottage industry } & Raw nuts & 80.0 & 40.0 & 40.0 & 5 \\
\hline & Roasted nuts & 0.0 & 0.0 & 0.0 & 8 \\
\hline & Peanut butter & 9.0 & 9.0 & 0.0 & 11 \\
\hline \multirow[t]{2}{*}{ Nairobi wholesale } & Unsorted nuts & 65.0 & 69.5 & 30.0 & 23 \\
\hline & Sorted nuts & 54.5 & 54.5 & 27.0 & 11 \\
\hline Nyanza markets & Unsorted nuts & 33.0 & 12.5 & 17.0 & 24 \\
\hline Mean & & 40.3 & 30.9 & 19.0 & \\
\hline
\end{tabular}

Aflatoxin contamination levels of groundnuts and peanut butter: There was variation in aflatoxin levels among groundnut and peanut butter samples ranging from 0.0 to $2377.1 \mu \mathrm{g} / \mathrm{kg}$ (Table 4). The wide variation in aflatoxin contamination in peanut butter could be attributed to contamination during processing in the cottage industry and using groundnuts that were already infected by aflatoxin-producing fungi. For instance, the processor whose peanut butter recorded the highest aflatoxin contamination did not grind roasted nuts immediately after roasting but stored them to grind later based on customer purchase orders. It was also observed that the processor had not cleaned the grinder after the previous peanut butter production. This practice could predispose the peanut butter to increased aflatoxin levels. On the other hand, the processor from whose peanut butter aflatoxins were not detected observed hygiene in processing and was also a trained food technologist. Defective nuts are more likely to be infected with aflatoxin-producing fungi than sound nuts (Whitaker et al., 1997). The presence of defective nuts in the current study was positively correlated $(r=0.412, p=$ $0.0092)$ with aflatoxin levels. The wide variation in aflatoxin contamination in unsorted raw groundnuts from Nyamakima market can therefore be attributed to the presence of varying degree of total defective nuts among the samples. The defective nuts are high 
risk components which contain higher concentration of aflatoxins. Among the samples from Nyamakima, the samples whose aflatoxin levels were below 10 $\mu \mathrm{g} / \mathrm{kg}$ had an average of $12.43 \%$ defective nuts while those whose aflatoxin levels exceeded $10 \mu \mathrm{g} / \mathrm{kg}$ had an average of $17.29 \%$ defective nuts. Among the raw groundnut samples, the Red types had lower total aflatoxin levels than the Pink types, though not significant. However, there was no significant $(P \geq$ 0.05 ) correlation between groundnut type and aflatoxin levels. Aflatoxin contamination increased along the value chain within the peanut cottage industry in Nairobi with raw groundnuts being the least contaminated followed by roasted nuts whereas peanut butter was the most contaminated. This was evidence that considerable aflatoxin contamination occurred during peanut butter processing. Improper handling practices during storage and processing have been reported to increase aflatoxin contamination in peanut butter in Sudan (Hanafi, 1987; Omer, 2001). In the present study, poor handling practices that were observed included failure to clean the grinder after peanut butter production, storing roasted nuts for long before grinding, and cooling of roasted nuts on the floor and/or outside in the open. Aflatoxin levels were significantly $(P \geq 0.05)$ higher for raw groundnuts from Nairobi than from Nyanza. This implies that the source of raw groundnuts used in the peanut butter cottage industry is a factor that predisposes peanut butter to aflatoxin contamination. It is possible that raw groundnuts were handled poorly in the country of origin or aflatoxin contamination occurred during transit. This observation was consistent with the findings of an earlier study by Mutegi et al. (2012) that reported higher aflatoxin levels in groundnut products sampled from Nairobi than from Nyanza. Negligence during post-harvest handling of groundnuts by market players along the market chain could lead to increase in aflatoxin contamination.

Roasting of groundnuts has been shown to reduce aflatoxin levels (Hamada \& Megalla, 1982; Yazdanpanah et al., 2005). The degree of reduction is dependent on heating time, temperature and the initial aflatoxin concentration (Rustom, 1997; Yazdanpanah et al., 2005; Arzandeh and Jinap, 2011). Ogunsanwo et al. (2004) observed that roasting significantly reduced the levels of aflatoxin $B_{1}$ and $G_{1}$ in groundnuts. In the study, groundnuts were dry-roasted at $150^{\circ} \mathrm{C}$ for 30 minutes which resulted in a $70 \%$ and $79.8 \%$ reduction of $\mathrm{AFB}_{1}$ and $\mathrm{AFG}_{1}$ respectively. However, roasting did not affect aflatoxin level in the peanut butter cottage industry in Nairobi. This could be attributed to recontamination of roasted groundnuts with aflatoxin-producing fungi due to poor hygiene practices in the cottage industry.

Correlation between Aspergillus section Flavi and aflatoxin contamination: There was a positive association $(r=0.3435)$ between the incidence of $A$. flavus $S$ strain and $r=0.4254$ for $A$. flavus $L$ strain and total aflatoxin level (Fig. 2). Aspergillus parasiticus was also positively correlated with total aflatoxin level. However, there was no significant $(p \geq$ 0.05 ) association between groundnut types and aflatoxin level.

Table 4: Aflatoxin level $(\mu \mathrm{g} / \mathrm{kg})$ of groundnut and peanut butter samples from various market outlets in Nairobi and Nyanza provinces, Kenya.

\begin{tabular}{lllrrr}
\hline Sample source & Sample description & Sample type & \multicolumn{2}{c}{ Aflatoxin level $(\boldsymbol{\mu g} / \mathbf{k g})$} & $\mathbf{n}$ \\
\cline { 3 - 5 } & & & \multicolumn{1}{c}{ Range } & Mean & \\
\hline Cottage industry & Raw nuts & Pink regular & $0.0-52.4^{\mathrm{a}}$ & 18.3 & 3 \\
& & Red regular & - & 5.0 & 1 \\
& & Red small & - & nd & 1 \\
& Roasted nuts & Red regular & $2.4-297.7$ & 54.8 & 8 \\
& Peanut butter & Paste & $0.0-2377.1$ & 318.3 & 11 \\
Nairobi wholesale & Unsorted nuts & Pink regular & $0.0-364.7$ & 111.2 & 11 \\
Outlets & & Red regular & $0.0-276.1$ & 89.1 & 12 \\
& Sorted nuts & Pink regular & $0.0-82.4$ & 24.0 & 4 \\
& & Red regular & $2.0-9.2$ & 5.3 & 5 \\
& & Red small & $6.0-7.8$ & 6.9 & 2 \\
Nyanza retail & Unsorted nuts & Pink large & $3.7-128.8$ & 71.6 & 3 \\
Outlets & & Pink regular & $0.0-229.8$ & 44.9 & 9 \\
& & Red regular & $0.0-14.0$ & 1.9 & 9 \\
& & Red mixed & & nd & 3 \\
\hline
\end{tabular}

a Limit of detection $(\mathrm{LOD})=0.5 \mu \mathrm{g} / \mathrm{kg} ; 0.0$ indicates below LOD; $\mathrm{nd}=$ not detected. 


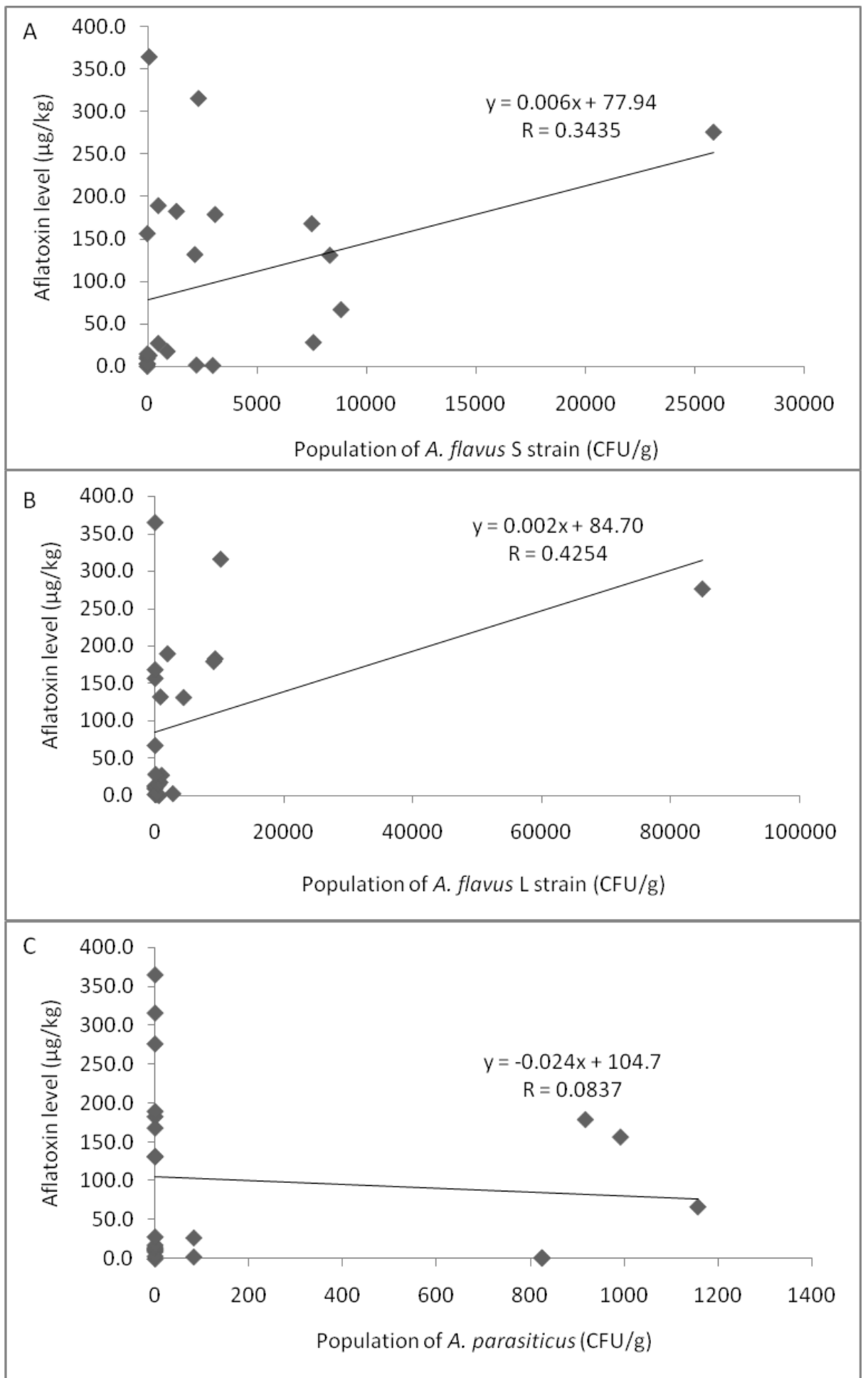

Figure 2: Scatter plot for the association between aflatoxin level $(\mu \mathrm{g} / \mathrm{kg})$ and $A$. flavus $\mathrm{S}$ strain $(\mathrm{A}) ; A$. flavus $\mathrm{L}$ strain (B); and $A$. parasiticus (C).

Conformance of the cottage industry to regulatory standards: Aflatoxin levels in 61 and $43 \%$ of the samples (Table 5) were above the EU and KEBS regulatory thresholds of 4 and $10 \mu \mathrm{g} / \mathrm{kg}$, respectively, implying that the samples would have been rejected under the respective regulations. This proportion of unsafe products is substantial in terms of economic loss if the products were to be discarded. However, 
Ndung'u et al. J. Appl. Biosci. 2013. Prevalence and aflatoxin contamination in groundnuts and peanut butter in Nairobi and Nyanza, Kenya

this rarely happens in Kenya due to poor monitoring and enforcement of regulatory standards. Groundnuts from Nyanza had the highest proportion (71\%) of samples that met the European safety limits. Unsorted raw groundnuts sampled from Nairobi wholesale markets and peanut butter from the cottage industry had the highest proportion $(74 \%$ and $73 \%$, respectively) of samples with aflatoxin levels above the KEBS regulatory limit of $10 \mu \mathrm{g} / \mathrm{kg}$. On the hand, sorted raw groundnuts from markets in Nairobi had the highest proportion (82\%) of samples with aflatoxin levels below $10 \mu \mathrm{g} / \mathrm{kg}$. The high proportion of unsafe products therefore implies that consumers of groundnuts and groundnut products in Kenya are invariably exposed to unsafe levels of aflatoxin. Besides the health implications, the high levels of aflatoxin in groundnuts are a barrier to trade. Groundnuts exported from Sudan to EU have previously been rejected owing to failure to meet aflatoxin standards (Hanafi, 1987). Thus, the purpose of reducing aflatoxin contamination levels in groundnuts should be to minimize food safety concerns and also for economic reasons (Ozay et al., 2008). A high proportion (80\%) of raw groundnut samples from the cottage industry had aflatoxin levels below $10 \mu \mathrm{g} / \mathrm{kg}$. Whereas aflatoxin level in half of the roasted groundnut samples from the cottage industry was below the $10 \mu \mathrm{g} / \mathrm{kg}$ limit, contamination level of $73 \%$ of peanut butter samples was above $10 \mu \mathrm{g} / \mathrm{kg}$. This showed increase in aflatoxin contamination within the peanut butter cottage industry.

Table 5: Proportion (\%) of groundnut and peanut butter samples with aflatoxin levels in different categories based on EU and KEBS standards.

\begin{tabular}{|c|c|c|c|c|}
\hline \multirow[t]{2}{*}{ Sample source } & \multirow[t]{2}{*}{ Sample description } & \multicolumn{3}{|c|}{ Aflatoxin level category $(\mu \mathrm{g} / \mathrm{kg})$} \\
\hline & & $\leq 4$ & $\leq 10$ & $>10$ \\
\hline \multirow[t]{3}{*}{ Cottage industry } & Raw nuts & 60 & 80 & 20 \\
\hline & Roasted nuts & 25 & 50 & 50 \\
\hline & Peanut butter & 18 & 27 & 73 \\
\hline Nairobi wholesale & Unsorted nuts & 22 & 26 & 74 \\
\hline Outlets & Sorted nuts & 36 & 82 & 18 \\
\hline Nyanza retail outlets & Unsorted nuts & 71 & 75 & 25 \\
\hline Mean & & 39 & 57 & 43 \\
\hline
\end{tabular}

\section{CONCLUSION}

Presence of defective nuts and the source of raw groundnuts predispose peanut butter to aflatoxin contamination in the cottage industry. Farmers need to be enlightened on proper ways of handling groundnuts during harvesting and threshing to avoid breakage of the nuts in order to reduce fungal infection. Sorting should be made mandatory for the groundnut marketers with effective monitoring to ensure compliance and punitive measures should be appended to non compliance. The Kenya Bureau of Standards should strengthen monitoring for

\section{ACKNOWLEDGEMENTS}

The authors thank USAID, through the Peanut Collaborative Research Support Program (peanut CRSP) funded by USAID cooperative agreement

\section{REFERENCES}

Abdelhamid AM, 1990. Occurrence of some mycotoxins (aflatoxin, ochratoxin A, citrinin, compliance to set standards and enforce regulations in the Nairobi peanut butter cottage industry. Awareness needs to be raised among the peanut butter processors to observe safety standards in processing so as to reduce aflatoxin contamination. Mechanisms for inspection and certification of imported groundnuts should be established accompanied by regular monitoring for aflatoxin levels of the imported groundnuts to ensure that they comply with set limits.

ECG-A-00-07-00001 for financial support in conducting this research, and ICRISAT for allowing us to use the aflatoxin laboratory to do analysis.

zearalenone and vomitoxin) in various Egyptian feeds. Arch Tierernahr 40: 647-64. 
Ndung'u et al. J. Appl. Biosci. 2013. Prevalence and aflatoxin contamination in groundnuts and peanut butter in Nairobi and Nyanza, Kenya

Antonio L, Antonio B, Giuseppina M, Antonio M, Giancarlo P, 2003. Epidemiology of toxigenic fungi and their associated mycotoxins for some Mediterranean crops. European Journal of Plant Pathology 109: 645 - 667.

AOAC, (2000). Official Methods of Analysis of the Association of Analytical Chemists. $17^{\text {th }}$ Edition. Washington, DC, USA.

Arzandeh S. and Jinap S, 2011. Effect of initial aflatoxin concentration, heating time and roasting temperature on aflatoxin reduction in contaminated peanuts and process optimization using response surface modeling. International Journal of Food Science and Technology 46: 485 - 491.

Bankole SA, Schollenberger M, Drochner W, 2006. Mycotoxin contamination in food systems in sub-Saharan Africa: A review. Mycotoxin Research 22: 163 - 169.

Baozhu G, Jiujiang Y, Corley $\mathrm{CH}$, Thomas $\mathrm{EC}$, William CN, Brian TS, 2009. Strategies in prevention of preharvest aflatoxin contamination in peanuts: aflatoxin biosynthesis, genetics and genomics. Peanut Science 36: 11 - 20

Campos-Mondragón MG, Calderón De La Barca AM, Durán-Prado A, Campos-Reyes LC, OliartRos RM, Ortega-García J, Medina-Juárez LA, Angulo O, 2009. Nutritional composition of new peanut (Arachis hypogaea L.) cultivars. Grasas Y Aceites, Abril-Junio 60: $161-167$.

CAST, 1989. Mycotoxins: Economic and health risks. Task force report 116. Council of Agricultural Science and Technology, Ames, IA.

Dickens JW, 1977. Aflatoxin occurrence and control during growth, harvest and storage of peanuts. Journal Series of the North Carolina Agricultural Experiment Station, Raleigh, N. Carolina 27607.

EC, 2010. European Commission. Commission regulation (EU) No. 165/2010 of 26 February 2010 amending Regulation (EC) No $1881 / 2006$ setting maximum levels for certain contaminants in foodstuffs as regards aflatoxins. Official Journal of European Communities L 50/8.

Ehrlich KC, Chang PK, Yu J, Cotty PJ, 2004. Aflatoxin biosynthesis cluster gene cypA is required for $G$ aflatoxin formation. Applied and Environmental Microbiology 70: 6518 6524.

FAO, 2001. Manual on the application of the HACCP system in mycotoxin prevention and control.
Food and Nutrition paper 73, ISSN 02544725. Rome.

Frisvad JC, Skouboe P,

Samson RA, 2005. Taxonomic comparison of three different groups of aflatoxin producers and a new efficient producer of aflatoxin $B_{1}$, sterigmatocystin and 3-Omethylsterigmatocystin, Aspergillus

rambellii sp. Nov. Syst. Applied Microbiology 28: 442-453.

Galvez FCF, Francisco MLDL, Villarino BJ, Lustre AO, Resurreccion AVA, 2003. Manual sorting to eliminate aflatoxin from peanuts. Journal of Food Protection 66: 1879 - 1884.

Gordon SS, 2003. Aflatoxin and food safety: Recent African perspectives. Promec Unit, Medical Research Council, Tygerberg, South Africa. Journal of Toxicology -Toxin Reviews 22: $264-268$.

Hamada AS, and Megalla E, 1982. Effect of malting and roasting on reduction of aflatoxin in contaminated soybeans. Mycopathologia 79: $3-6$.

Hanafi MO, 1987. Prevention and control of aflatoxin in Sudan. Joint FAO/WHO/UNICEF second international conference. p. 10.

Hedayati M, Pasqualotto AC, Warn PA, Bowyer P, Denning DW, 2007. Aspergillus flavus: human pathogen, allergen and mycotoxin producer. Microbiology 153: 1677 - 1692.

Horn BW. and Dorner JW, 1998. Soil populations of Aspergillus species from section Flavi along a transect through peanut-growing regions of the United States. Mycologia 90: 767 - 776.

Jolly PE, Jiang Y, Ellis MO, Awuah RT, Appawu J, Nnedu O, Stilles JK, Wang JS, Adjei O, Jolly $\mathrm{CM}$, Williams JH, 2007. Association between aflatoxin exposure and health characteristics, liver function, hepatitis and malaria in Ghanaians. Journal of Nutritional and Environmental Medicine 16: 242-257.

Kaaya AN, Harris C, Eigel W, 2006. Peanut aflatoxin levels on farms and in markets of Uganda. Peanut Science 33: 68 - 75.

Kane A, Ba-Diop N, Diack TS, Sembene M, Delobel A, Guiro AT, 2006. Relationship between the condition of home-stored peanuts and aflatoxin B1 contamination. In Mycotoxins and Phycotoxins: Advances in Determination, Toxicology, and Exposure Management: Proceedings of the Xlth International IUPAC Symposium on Mycotoxins and Phycotoxins, May 17-21, 2004, Bethesda, Maryland, USA (p. 53). Wageningen Academic Publishers. 
KEBS, 2007. Kenya Standard KS 694-1: 2007. Shelled groundnut (Arachis hypogaea Linn.) - Specification. Part 1: Raw Groundnut for Table Use. Kenya Bureau of Standards Documentation Centre, Nairobi, Kenya.

KEBS, 2009a. Kenya Bureau of Standards. Kenya Standard KS 686: 2009, ICS 67.080.10. Peanut butter - Specification. Kenya Bureau of Standards Documentation Centre, Nairobi, Kenya.

KEBS, 2009b. Kenya Bureau of Standards. Kenya draft standard KS 05-1500: 2009, ICS 67.020 . Code of practice for hygiene in the food and drink manufacturing industry. Kenya Bureau of Standards Documentation Centre, Nairobi, Kenya.

Kladpan S, Mahakachanakul W, Yongmanitchai V, Boonyaratanakornkit M, Chinbuti A, 2004. Situation of aflatoxin contamination in groundnut products in Thailand in 2004 Proceedings of the 43rd Kasetsart University annual conference, Thailand, 1-4 February, 2005. p. $557-564$.

Krishnan S, Manavathu EK, Chandrasekar PH, 2009. Aspergillus flavus: an emerging nonfumigatus Aspergillus species significance. Mycoses 52: $206-222$.

Mehan VK, McDonald D, Haravu LJ, Jayanthi S, 1991. The groundnut aflatoxin problem: review and literature database. Patancheru, A. P. 502 324, India: p. 3.

Mutegi CK, 2010. The Extent of aflatoxin and Aspergillus Section Flavi, Penicillium spp. and Rhizopus spp. Contamination of peanuts from households in western Kenya and the causative factors of contamination. $\mathrm{PhD}$ Thesis, African Centre for Food Security, School of Agricultural Sciences and Agribusiness, Faculty of Science and Agriculture, University of KwaZulu-Natal, Pietermaritzburg, South Africa, p. 8.

Mutegi CK, Ngugi HK, Hendriks SL, Jones RB, 2009. Prevalence and factors associated with aflatoxin contamination of peanuts from Kenya. International Journal of Food Microbiology 130: 27 - 34.

Mutegi CK, Ngugi HK, Hendriks SL, Jones RB, 2012. Factors associated with the incidence of Aspergillus section Flavi and aflatoxin contamination of peanuts in the Busia and Homa bay districts of western Kenya. Plant Pathology 61: $1143-1153$.

Mutegi C, Kimani J, Otieno G, Wanyama R, Christie ME, Mallikarjunan K, Kaaya A, 2010. Peanut aflatoxin levels under different market attributes. East African Agricultural and Forestry Journal 77: $95-103$.

Mirocha CJ, and Christensen CM, 1974. Fungus metabolites toxic to animals. Annual Review of Phytopathology 12: $303-330$.

Ogunsanwo BM, Faboya OOP, Idowu OR, Lawal OS, Bankole SA, 2004. Effect of roasting on the aflatoxin contents of Nigerian peanut seeds. African Journal of Biotechnology 3 : 451-455

Okello DK, Kaaya AN, Bisikwa J, Were M, Oloka HK, 2010. Management of aflatoxins in groundnuts: A manual for farmers, processors, traders and consumers in Uganda. National Agricultural Research Organization, Entebbe, Uganda.

Omer RE, 2001. Peanut butter consumption and hepatocellular carcinoma in Sudan. PhD Thesis, Wageningen University, Grafisch Bedrijf and Looijen B.V. Publisher, Wageningen, Netherlands.

Omer RE, Bakker MJ, Van'tveer P, Hooganboom RLAP, Polman THG, Alink GM, Idris MO, Kadaru AMY, Kok FJ, 2001. Aflatoxin and liver cancer in Sudan. Nutrition and Cancer 32: 174-80.

Ozay G, Seyhan F, Pembeci C, Saklar S, Yilmaz A, 2008. Factors influencing fungal and aflatoxin levels in Turkish hazelnuts (Corylus avellana L.) during growth, harvest, drying and storage: A 3-year study. Food Additives and Contaminants 25: $209-218$

Pasqualotto AC, Denning DW, 2008. An aspergilloma caused by Aspergillus flavus. Medical Mycology 46: 275 - 278.

Passone MA, Rosso LC, Ciancio A, Etcheverry M, 2010. Detection and quantification of Aspergillus section Flavi spp. in stored peanuts by real-time PCR of nor-1 gene, and effects of storage conditions on aflatoxin production. International Journal of Food Microbiology 138: 276 - 281.

Polixeni V. and Panagiota M, 2008. Aflatoxin B1 and ochratoxin $A$ in breakfast cereals from Athens market: Occurrence and risk assessment. Lab of food chemistry, Department of chemistry, University of Athens, Panepistimiopolis, 15784 Athens, Greece.

Ribeiro J, Cavaglieri L, Fraga M, Direito G, Dalcero A, Rosa C, 2006. Influence of water activity, temperature and time on mycotoxins production on barley rootlets. Letters in Applied Microbiology 42: 179 - 184. 
Raper LB and Fennell DI, 1965. The Genus Aspergillus. The Williams \& Wilkins Co. Baltimore. p. 686.

Ros E, 2010. Health benefits of nut consumption. Nutrients 2: 652 - 682.

Rustom IYS, 1997. Aflatoxin in food and feed: occurrence, legislation and inactivation by physical methods. Food Chemistry 59: 57 67.

Schroeder HW. and Boller RA, 1973. Aflatoxin production of species and strains of the Aspergillus flavus group isolated from field crops. Applied and Environmental Microbiology 25: 885 - 889 .

Smith JE. and Moss MO, 1985. Mycotoxins: formation, analysis and significance. John Wiley \& sons. Chichester, Britain, p. 83 103.

Turner PC, Sylla A, Gong YY, Diallo MS, Sutcliffe AE, Hall AJ, Wild CP, 2005. Reduction in exposure to carcinogenic aflatoxins by post harvest intervention measures in West Africa: A community-based intervention study. Lancet 365: 1950 - 1956.

Varga J, Frisvad JC, Samson RA, 2012. Two new aflatoxin producing species and an overview of Aspergillus section Flavi. Studies in Mycology 69: $57-80$.

Wagacha JM. and Muthomi JW, 2008. Mycotoxin problem in Africa: Current status, implications to food safety and health and possible management strategies International Journal of Food Microbiology 124: $1-12$.

Waliyar F. and Reddy SV, 2009. Training manual on "Aspergillus flavus seed infection and aflatoxin estimation by ELISA" and aflatoxin management options in groundnut. International Crops Research Institute for the Semi-Arid Tropics. Patancheru 502324 Andhra Pradesh, India, 16.

Whitaker T, Giesbrecht H.Jr., Francis W, Dorner J, Dowell F, Cole R, 1997. Estimating aflatoxin in farmers' stock peanut lots by measuring aflatoxin in various peanut grade components. Available at http://www.ars.usda.gov/research/publication s/publications.htm?seq_no_115=79217.

Yazdanpanah H, Mohammadi T, Abouhossain G, Cheraghali AM, 2005. Effect of roasting on degradation of aflatoxins in contaminated pistachio nuts. Food and Chemical Toxicology 43: $1135-1139$ 
Ndung'u et al. J. Appl. Biosci. 2013. Prevalence and aflatoxin contamination in groundnuts and peanut butter in Nairobi and Nyanza, Kenya

Table 2: Population (CFU/g peanuts) of fungal species isolated from groundnuts and peanut butter sampled from Nairobi and Nyanza provinces in Kenya.

\begin{tabular}{|c|c|c|c|c|c|c|c|c|c|c|c|}
\hline Sample source & $\begin{array}{l}\text { Sample } \\
\text { description }\end{array}$ & 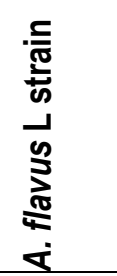 & 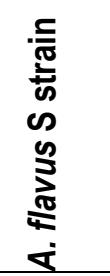 & 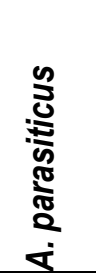 & 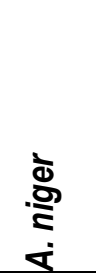 & 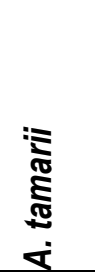 & 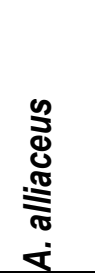 & 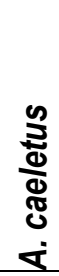 & 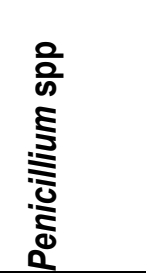 & 咅 & 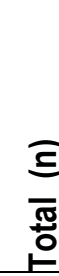 \\
\hline \multirow[t]{3}{*}{ Cottage industry } & Raw nuts & $1132 a$ & $582 a b$ & $265 a$ & $17 a$ & $34 a$ & $0 \mathrm{a}$ & $0 \mathrm{a}$ & $64697 a$ & $26558 a$ & 5 \\
\hline & Roasted nut & $\mathrm{Ob}$ & ob & $0 a$ & $0 a$ & $0 \mathrm{a}$ & $0 \mathrm{a}$ & $0 \mathrm{a}$ & $238 c$ & $884 b$ & 8 \\
\hline & Peanut butter & $76 b$ & $8 b$ & $0 a$ & $0 a$ & $0 a$ & $0 \mathrm{a}$ & $0 \mathrm{a}$ & $323 b c$ & $3023 a b$ & 11 \\
\hline \multirow[t]{2}{*}{ Nairobi wholesale } & Unsorted nuts & $5505 a$ & $3229 a$ & $212 a$ & $359 a$ & $398 a$ & $149 a$ & $4 a$ & 17059ab & $34209 a$ & 23 \\
\hline & Sorted nuts & $106 a b$ & $204 a b$ & $204 a$ & $61 a$ & $0 a$ & $0 \mathrm{a}$ & $0 \mathrm{a}$ & $3446 a b c$ & $31262 a$ & 11 \\
\hline Nyanza retail & Unsorted nuts & $559 a b$ & $111 b$ & $52 a$ & $49 a$ & $0 \mathrm{a}$ & $0 \mathrm{a}$ & $0 \mathrm{a}$ & $14688 b c$ & $21954 a$ & 24 \\
\hline Mean & & 1230 & 689 & 122 & 81 & 72 & 25 & 1 & 16742 & 19648 & \\
\hline
\end{tabular}

Means accompanied by the same letter(s) within the column are not significantly different $(p \geq 0.05)$. 